\title{
Synthesis of cyclic nitrones by bromocyclization of unsaturated oximes
}

\author{
Mahendra Gulla, Lars Bierer, Leo Redcliffe, Stefan Schmidt, and Volker Jäger* \\ Institut für Organische Chemie, Universität Stuttgart, Pfaffenwaldring 55, \\ D-70569 Stuttgart, Germany \\ E-mail: jager.ioc@oc.uni-stuttgart.de
}

\begin{abstract}
The bromocyclization of several $\gamma, \delta$-unsaturated oximes leads to respective bromomethylpyrroline N-oxides. Yields vary from 23 to $87 \%$, depending on the structural features. An unusual formal $\mathrm{N}$-endo cyclization is found with a $\beta, \gamma$-enoxime. As a consequence, reversal of steps, i. e. addition of $\mathrm{Br} / \mathrm{OH}$ to the $\mathrm{C}=\mathrm{C}$ bond of the unsaturated aldehyde first, followed by oximation, opens access to 6-membered nitrones.
\end{abstract}

Keywords: Unsaturated oximes, bromocyclization, cyclic nitrones, endo/exo-cyclization

\section{Contents}

Introduction

1. Bromocyclization of a D-erythro-4-pentenose oxime

2. Exploring the scope of enoxime bromocyclization

3. Bromocyclization of an $\alpha, \gamma$-enoxime: exo-vs. endo-cyclization

4. Reversed regioselectivity of $\mathrm{N}$-cyclization to involve the chain terminus

5. Closing remarks

\section{Introduction}

Nitrones are versatile intermediates in organic synthesis since the addition of C-nucleophiles or dipolarophiles occurs with ease and may be used to assemble complex structures. ${ }^{1}$ With (endo)cyclic nitrones, often derived from carbohydrate or related chiral starting materials, this has extensively been used in, e.g., for approaches to alkaloids such as indolizidine or pyrrolizidine polyols. Several of these structures exhibit remarkable biological activities, notably as inhibitors of glycosidases. . $^{2,3}$ 
For access to cyclic nitrones many methods are described in the literature, ${ }^{1}$ including the oxidation of - already cyclic - amines or hydroxylamines, ${ }^{1,4}$ intramolecular condensation of $\omega$ hydroxylamino-carbonyl derivatives, ${ }^{1,5}$ and, most interesting, cyclizations of $\omega$-unsaturated oximes. The latter approaches may involve nucleophilic $\mathrm{N}$-addition of the oxime part to an acceptor-substituted double bond. ${ }^{6}$ Further, intramolecular nucleophilic substitution of a suitable leaving group by the oxime nitrogen atom, such as provided by epoxide, ${ }^{7}$ iodide, ${ }^{8}$ or mesylate, ${ }^{9,10}$ has seen many applications.

A most attractive route to cyclic nitrones is based on acyclic $\omega$-alkenyloximes. First, addition of a suitable electrophile to the $\mathrm{C}=\mathrm{C}$ bond forms a cyclic "onium" ion (or an open-chain cationic species) which is intercepted intramolecularly by the oxime nitrogen atom. The pioneering investigations in this field are due to Grigg and his group who systematically studied such $\mathrm{N}$-addition of oximes to $\omega$-unsaturated systems with a wide range of electrophiles. Thus, mercuric acetate, ${ }^{11}$ phenylselenenyl bromide, ${ }^{6 b, 12}$ bis(acetonitrile) palladium(II) chloride, ${ }^{13} \mathrm{~N}-$ bromo- and $\mathrm{N}$-iodosuccinimide, ${ }^{12 \mathrm{~b}, 14}$ iodine, ${ }^{6 \mathrm{~b}, 14}$ or iodine chloride ${ }^{14}$ were employed to trigger the addition/cyclization process. With some halogen reagents, the $(E) /(Z)$ ratio of the starting oximes was reflected in the product distribution, often consisting of the cyclic nitrone as the major and the dihydro-[4H]-1,2-oxazine as the minor product(s) ${ }^{12,14}$ (Scheme 1).

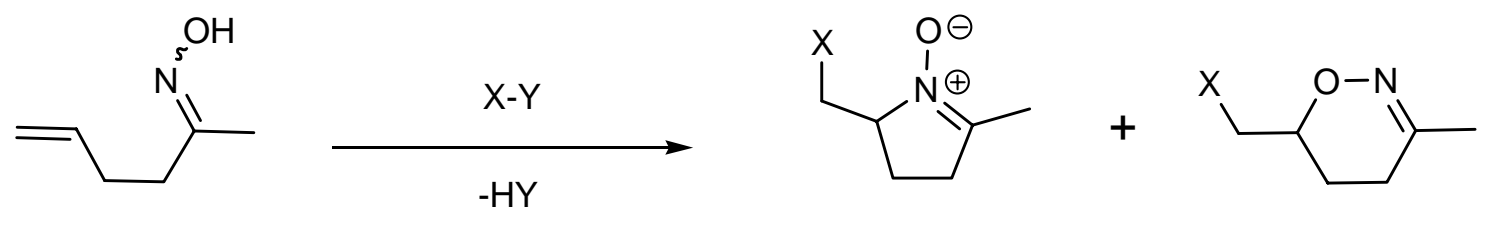

X-Y: $\mathrm{Hg}(\mathrm{OAc})_{2}, \mathrm{PhSeBr}, \mathrm{I}_{2}, \mathrm{~N}$-bromosuccinimide

Scheme 1. Cyclization of alkenyl oximes induced by electrophiles.

During our efforts to conceive new structures with strong and selective inhibition of glycosidases, we have found that amino-hydroxymethyl-cyclopentanetriols are highly active to that respect concerning the gluco, manno, galacto, xylo, and GlcNAc series, but less so with regard to fucosidases. ${ }^{15,16}$ We have therefore proposed several new structures of presumed activity in this field, notably based on 1,4-iminopentitols substituted at the N-and 1-positions. ${ }^{3}$ Indeed, in the fuco series strong inhibitors were found with a series of $\alpha$-1-substituted L-lyxitols, derived from an L-lyxo-bromomethylpyrroline $\mathrm{N}$-oxide. This cyclic nitrone was obtained by bromocyclization of a ribose-derived 4-pentenose oxime as disclosed previously. ${ }^{3}$ 


\section{Bromocyclization of a D-erythro-4-pentenose oxime}

Our efforts started in 1994, with the ribose-derived unsaturated oxime, ${ }^{3,17}$ a substrate that had meanwhile been used also by Wightman et al. for benzeneselenenyl bromide- and iodine-induced cyclizations. ${ }^{6 \mathrm{~b}}$ While the former gave a 1:1 mixture of separable cis/trans products (L-lyxo/Dribo) in $45 \%$ yield, the iodine-effected process was reported to proceed in "poorer combined yield" of a 3:5 iodomethylnitrone mixture. ${ }^{6 \mathrm{~b}}$ Our experiments had led to a more favourable ca. 60 $\%$ yield of diastereomeric nitrones in a 67:33 ratio., 3,18 These iodo compounds, however, were not readily separable, they proved unstable on storage, and they did not lead to clean consecutive products (Scheme 2).
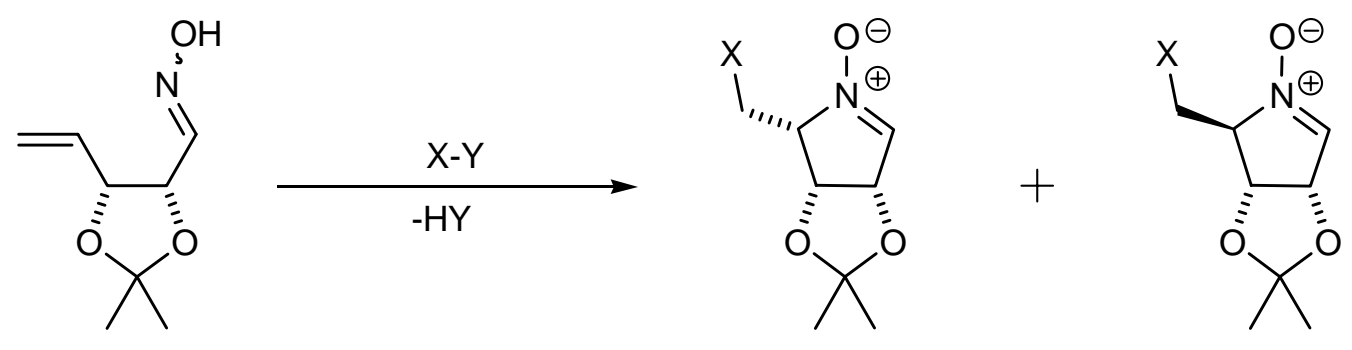

PhSeBr; d. r. 1:1, $45 \%$

$\mathrm{I}_{2}$, d. r. 1:1, "poorer yield"

$\mathrm{I}_{2}, \mathrm{NaHCO}_{3}$, d. r. 67:33, $60 \%$

Scheme 2. Cyclization of D-erythro-4-pentenose oxime acetonide.

Other initiators were tried, for example palladium dichloride in methanol which, however, only led to a dimethyl acetal. ${ }^{17 a}$ With bromonium di-sym-collidine hexafluorophosphate ${ }^{19}$ in dichloromethane, decomposition of the ene-oxime was observed. ${ }^{18}$ The use of Nbromosuccinimide led to a mixture of the two diastereomeric pyrroline N-oxides along with two tetrahydrooxazines, ${ }^{18}$ similar to Grigg's findings. ${ }^{14}$ At last the use of bromine - not reported before - proved more promising, and after some optimization conditions using 1.05 equivalents of bromine in the presence of sodium bicarbonate in dichloromethane resulted in good conversion, to yield an 83:17 mixture of L-lyxo/D-ribo nitrones (66\% and $14 \%$ of isolated, crystalline products). ${ }^{3,18}$ The nitrones obtained by this bromocyclization were separated by MPLC; both isomers were crystalline and their configurations were ascertained by NMR data and crystal structure determination (Scheme 3 ). ${ }^{20}$ 

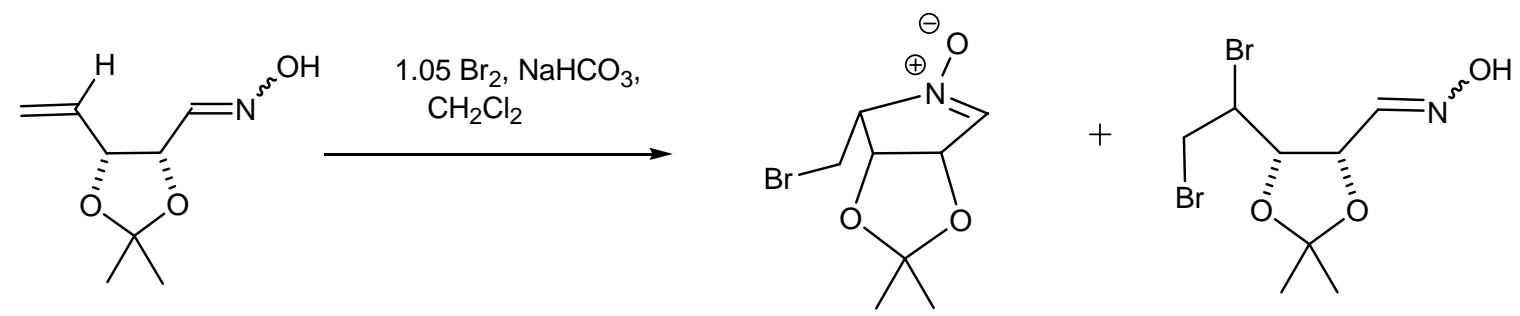

$$
\begin{array}{rr}
0{ }^{\circ} \mathrm{C}: & >97 \\
& {[84: 16]} \\
-80{ }^{\circ} \mathrm{C}: & 71 \\
& {[86: 14]}
\end{array}
$$
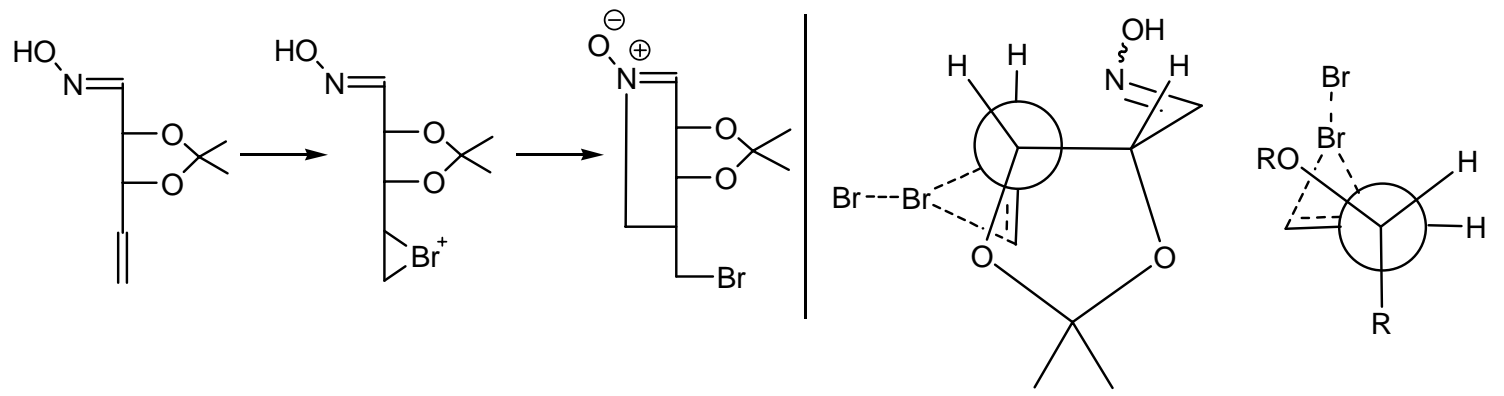

\section{Scheme 3}

The stereoselective outcome of this procedure with bromine was more favourable than with the use of iodine. We have studied this key reaction at various temperatures which showed that there was substantial formation of bromine adducts at $-80{ }^{\circ} \mathrm{C}(29 \%){ }^{21}$ Attack of bromine to the $\alpha$-oxygenated $\mathrm{C}=\mathrm{C}$ bond should be slowed down by the inductive, electron-withdrawing effect of the $\alpha$-alkoxy group on the $\pi$-system. This unfavourable interaction would be maximized in the anti-OR conformation due to $\sigma^{*}, \pi$-interaction, similarly as shown with nitrile oxide (electrophile) cycloadditions to allyl-substituted alkenes or, with Sharpless' asymmetric epoxidation of allylic alcohols. $^{22}$

Thus, bromonium ion formation would preferably lead to a species with ribo (cis; "anti") configuration, and the ensuing attack of the oxime nitrogen atom would invert the C4 stereocentre to yield the lyxo (trans; "syn") product. On the other hand, if bromine addition would prevail, the dibromide would be formed first, and bromine substitution at $\mathrm{C} 4$ by the oxime nitrogen atom would have to follow - this would imply a different stereochemical course of the initial bromine attack and would be in contrast to results of many related additions to $\alpha$-xsubstituted olefins.

A further argument here would be that $\mathrm{N}$ - and also O-attack should then face a dibromide terminus - $\mathrm{CHBr}-\mathrm{CH}_{2} \mathrm{Br}$, with a secondary and a primary bromide part, and that substitution/ cyclization then should occur equally well or better at the bromomethyl carbon site (vide infra). 


\section{Exploring the scope of enoxime bromocyclization}

With the lyxo-bromomethylnitrone secured, systematic exploration of structures concerning fucosidase inhibition was possible, as reported briefly ${ }^{3,23}$ (and to be discussed in detail elsewhere). On the other hand, it seemed promising to explore the scope of this bromocyclization. To this respect several unsaturated oximes with different structural features were prepared and submitted to the action of bromine under standard conditions, i. e. treatment with 1.05 equivalents of bromine in the presence of sodium bicarbonate ( 3 equivalents) at $0{ }^{\circ} \mathrm{C}$ to room temperature (see Scheme 4).
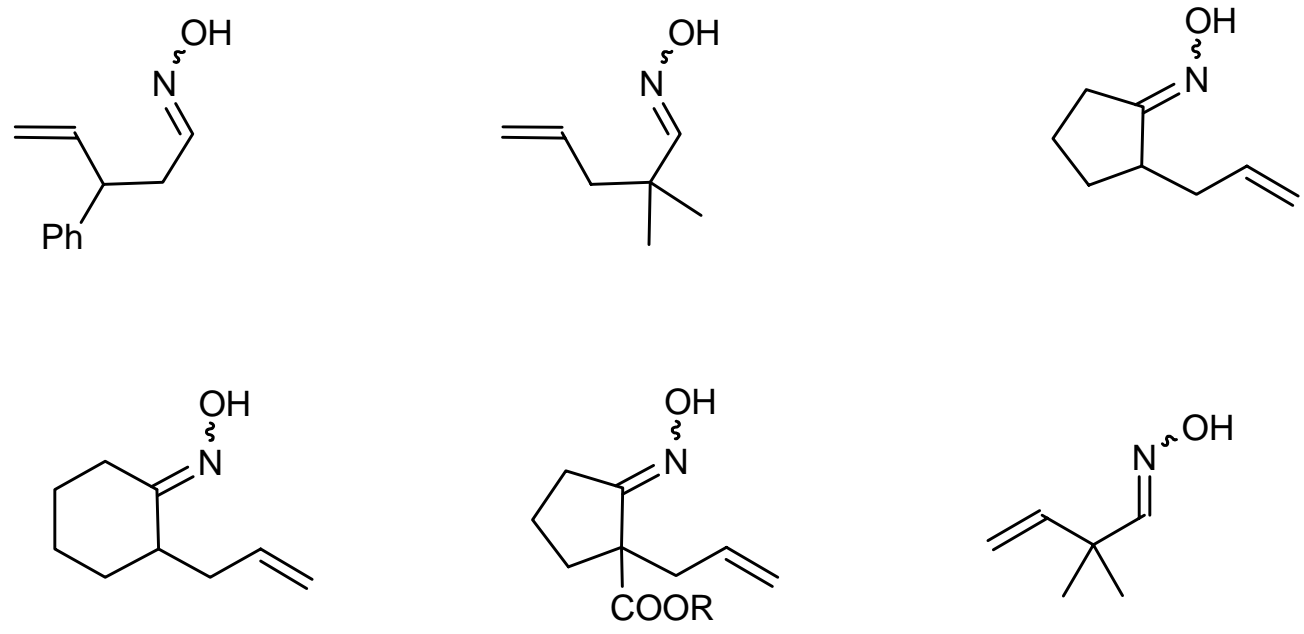

$$
\mathrm{R}=\mathrm{Et},{ }^{\mathrm{t}} \mathrm{Bu}
$$

Scheme 4. Further unsaturated oximes used for bromocyclizations

The 3-phenyl-4-pentene aldoxime under these conditions led to a mixture of two diastereomeric nitrones in a 60:40 ratio in low yield (23\%), besides acyclic material.
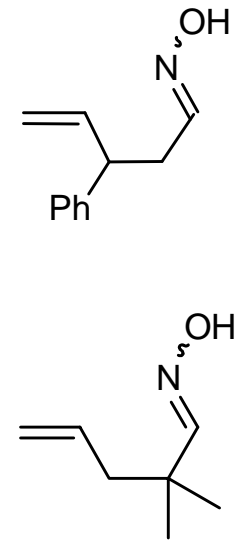
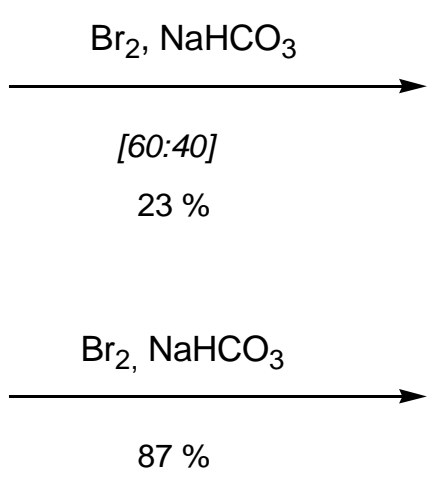<smiles>[O-]N1CCC(c2ccccc2)C1CBr</smiles><smiles></smiles>

\section{Scheme 5}


In order to facilitate such cyclization, a gem-dimethyl unit was introduced to take advantage of the Thorpe-Ingold effect. ${ }^{24}$ Indeed, the 2,2-dimethyl-4-pentene aldoxime afforded the 5-membered bromomethylnitrone as a crystalline substance in high yield (87\%) (Scheme 5).

Similarly, with the conformationally restricted allylcyclopentanone oxime cyclization was expected to occur easily, but the resulting bicyclic nitrone could not be obtained in pure form, due to facile decomposition. Its formation was proven by treating the crude product mixture with excess sodium borohydride in ethanol; the resulting bicyclic bromomethyl-N-hydroxypyrrolidine was then isolated in $31 \%$ yield after chromatography on silica (Scheme 6).
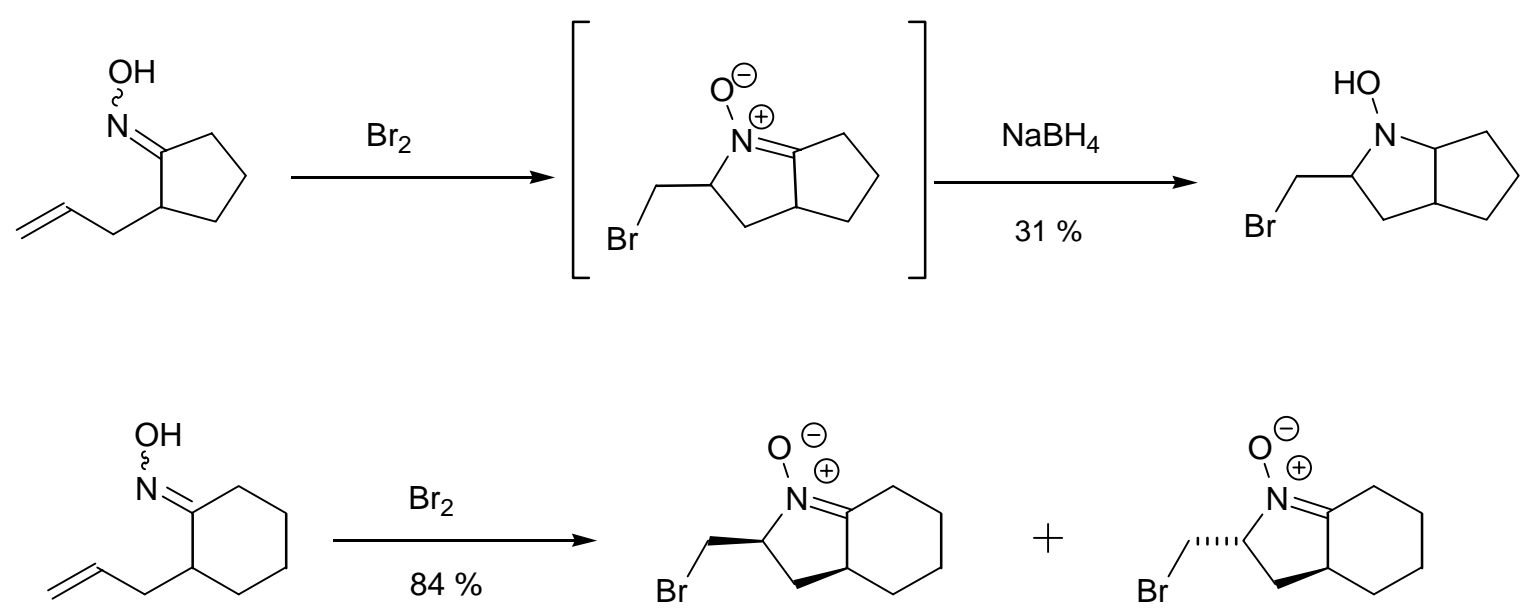

[67:33]

\section{Scheme 6}

The low yield of the [3.3.0]-bicyclic pyrroline $\mathrm{N}$-oxide in this case is attributed to an unfavourable cyclization step and also to consecutive reactions of this strained, hence more reactive nitrone. In accord with this, the allylcyclohexanone oxime was smoothly transformed to the [4.3.0]-bicyclic nitrone, which was obtained as a 67:33 mixture of cis/trans isomers (Scheme $6)$.

The allylcyclopentanone oxime had been prepared from the $\beta$-ketoester by allylation followed by hydrolysis and decarboxylation of the intermediate $\beta$-keto acid. Cyclization of the $\alpha$ allyl $\beta$-oximino ethyl ester itself was attempted also, since the resulting ester with a $\beta$-nitrone function would represent an immediate precursor of novel $\beta$-amino acid structures. In fact, cyclization occurred readily on bromine treatment, but after work-up and chromatographic separation the bicyclic nitrone ethyl ester was isolated in $19 \%$ yield only, besides another, less polar product. According to spectral data and, notably, a crystal structure determination, this constituted a cyclic bromomethyl-spirolactone, with intact oximino group (Scheme 7). The oxime nitrogen thus exhibits somewhat less tendency for nucleophilic attack on the (presumed) bromonium ion, as compared to the ester oxygen atom which undergoes bromolactonization. 
Actually, halolactonization of unsaturated esters is well precedented: ${ }^{24 c, 25}$ The alkoxy group OR of the cyclized product formed first (a dialkoxyoxonium ion) looses $\mathrm{R}$ either by substitution on attack of halide, or by splitting off a stabilized carbocation (such as benzyl). Related de-benzylations or de-allylations of respective unsaturated O-substituted oximes have been observed on treatment with phenylselenenyl bromide by Grigg et al. and have been mentioned as "fragmentation". ${ }^{26}$

Next, the tert-butyl ester of the $\alpha$-allyl cyclopentanone oxime was tested - the tert-butyl group might change the competing pathways in lending more volume, hence, less nucleophility to the ester group. In fact, the course of the cyclization was shifted towards bromolactonization which now amounted to $57 \%$ of bromomethyl-lactone and only $11 \%$ of nitrone (Scheme 7).

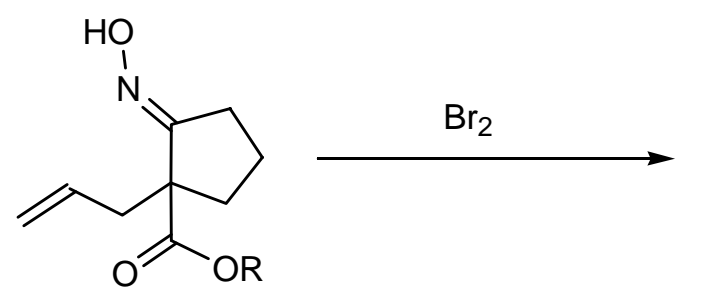

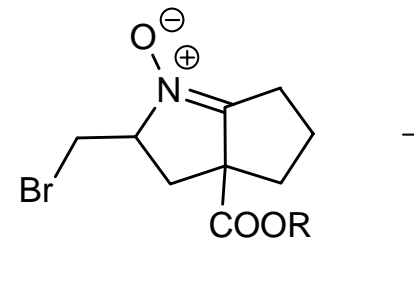

$\begin{array}{ll}\text { Et : } & 19 \% \\ { }^{t} \text { Bu: } & 11\end{array}$

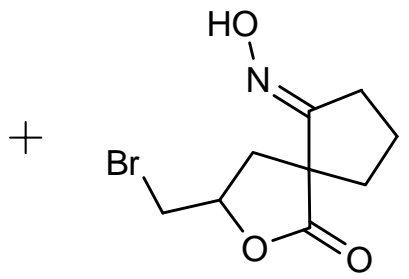

$+\quad 22 \%$

$+\quad 57 \%$

\section{Scheme 7}

\section{Bromocyclization of a $\beta, \gamma$-enoxime: exo-vs. endo-cyclization}

The alkenyloximes are present as $(E) /(Z)$ mixtures which apparently are equilibrated under the reaction conditions, to furnish only or predominantly $\mathrm{N}$-cyclized products, i. e. nitrones. This is the case when $\mathrm{PhSeBr},{ }^{12}$ bis(acetonitrile) palladium(II) chloride, ${ }^{13}$ iodine, ${ }^{14}$ or now bromine are employed as electrophilic initiators. With N-bromo succinimide, however, both the nitrone from N-cyclization - and the cyclic oxime ether (tetrahydrooxazine) - from O-attack - were obtained in ratios reflecting the original composition of $(\mathrm{E}) /(\mathrm{Z})$ oximes (vide supra).

Further, only the exo-tet ring-closures ${ }^{27}$ are observed, through attack to the more substituted carbon atom of the three-membered onium ion. It seemed of interest therefore to probe all this, with a $\beta, \gamma$-unsaturated oxime as substrate. The "usual" $\mathrm{N}$-cyclization would lead to a 4-membered nitrone, a known class of compounds with a tendency to dimerize. ${ }^{28}$ The inherent ring-strain - for cyclobutene and cyclopentene values of 30 and $7 \mathrm{kcal} / \mathrm{mole}$, respectively, are estimated $^{29}$ - might, however, defeat this mode of cyclization. Thus, the oxime of 2,2-dimethyl4-butenal was prepared and treated with bromine as usual. After chromatography on silica, a colourless, crystalline compound was obtained in low yield (29\%). This, according to a strong IR absorption at $1588 \mathrm{~cm}^{-1}$ and NMR signals at $6.76 \mathrm{ppm}\left({ }^{1} \mathrm{H}\right)$ and $145.5 \mathrm{ppm}\left({ }^{13} \mathrm{C}\right)$, did contain a nitrone moiety. The ${ }^{13} \mathrm{C}$ NMR triplet of the methylene group, however, was found at $68.7 \mathrm{ppm}$, 
the aliphatic methine absorption was registered at $49.2 \mathrm{ppm}$. These data preclude the cyclic oxime structures from O-cyclization, but also that of a four-membered nitrone from exo-Ncyclization. The data are in excellent accord, however, with the structure of the 5-membered nitrone, i. e. the bromo-dimethylpyrroline N-oxide! (Scheme 8).
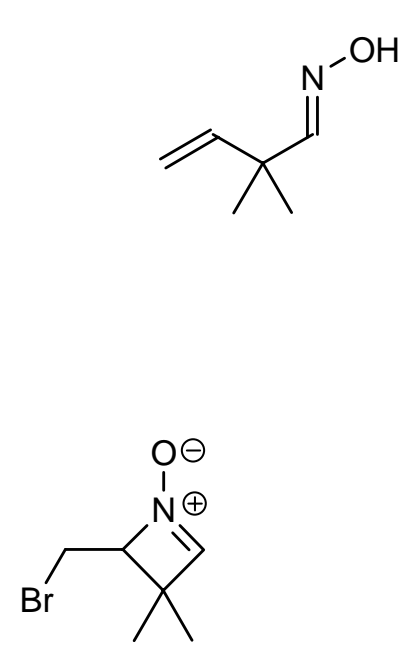

"N-exo"
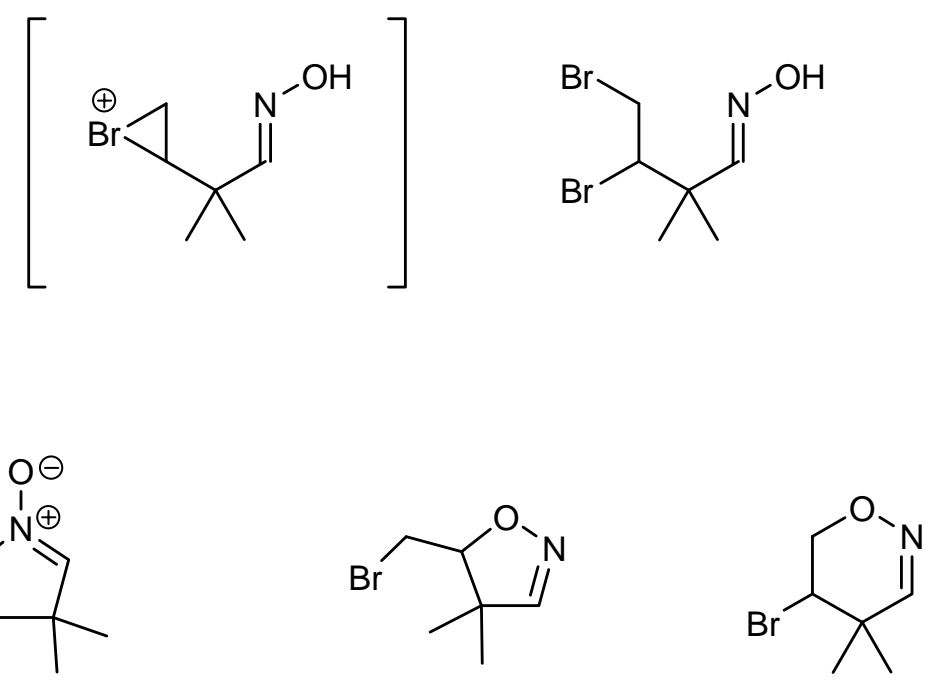

"N-endo"

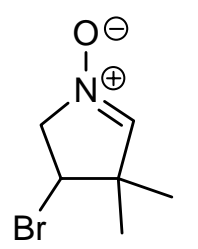

"O-exo"<smiles>CC(C)(/C=N/O)C(Br)CBr</smiles>

Scheme 8. Possible intermediates and modes of bromocyclization of 2,2-dimethyl-3-butene aldoxime

This is rationalized as follows: Exo-cyclization of the initial bromonium-oxime by internal $\mathrm{N}$-attack is slow as compared to ring-opening by (external) bromide ion, and the dibromide is formed. A relatively strain-free $\mathrm{N}$-cyclization to the terminal $\mathrm{CH}_{2} \mathrm{Br}$ group is now possible, and favoured over attack at the secondary $\mathrm{CHBr}$ site. This view is supported by the fact that the crude product mixture contains a substantial amount of open-chain dibromo-oxime as evidenced by NMR data. - As predictable with the other new nitrones described here, there is a large number of interesting transformations and applications to synthesis awaiting future work.

\section{Reversed regioselectivity of $\mathrm{N}$-cyclization to involve the chain terminus}

With $\gamma, \delta$-unsaturated oximes the cyclizations induced by electrophiles lead to 5-membered nitrones, observing the exo-cyclization mode without exception. ${ }^{11,12,14}$ The latter also applies to $\delta, \varepsilon$-enoximes where piperideine $\mathrm{N}$-oxides are formed. It would be desirable though to have a choice concerning products from endo-cyclization. A first example for this was discovered by chance with the 2,2-dimethyl-3-butenal substrate, vide supra. A suitable substrate to probe this is 3,3-dimethyl-4-butenal; its oxime led to a high yield of the bromomethyl nitrone (Scheme 5). 
Now the aldehyde was treated with N-bromosuccinimide in dimethyl sulfoxide/water forming the bromohydrin (present as the hemiacetal) as expected. ${ }^{25,30}$ This was transformed into the 5bromo-oxime with hydroxylamine without problems; the dibromoalkyl-oxime was isolated in 71 $\%$ yield and then heated to reflux in $\mathrm{CH}_{2} \mathrm{Cl}_{2}$ with sodium bicarbonate. Indeed, cyclization occurred smoothly, and the 6-membered nitrone was secured in $73 \%$ yield in analytically pure form (Scheme 9).

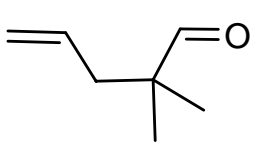

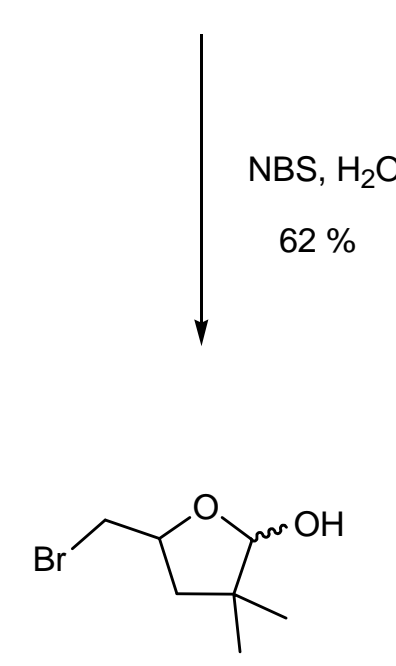

1. $\mathrm{NH}_{2} \mathrm{OH} \cdot \mathrm{HCl}, \mathrm{NaOAC}$

$$
\mathrm{CH}_{3} \mathrm{CN} / \mathrm{H}_{2} \mathrm{O} \quad 78 \%
$$

2. $1.05 \mathrm{Br}_{2}, \mathrm{NaHCO}_{3}$, $\mathrm{CH}_{2} \mathrm{Cl}_{2}$
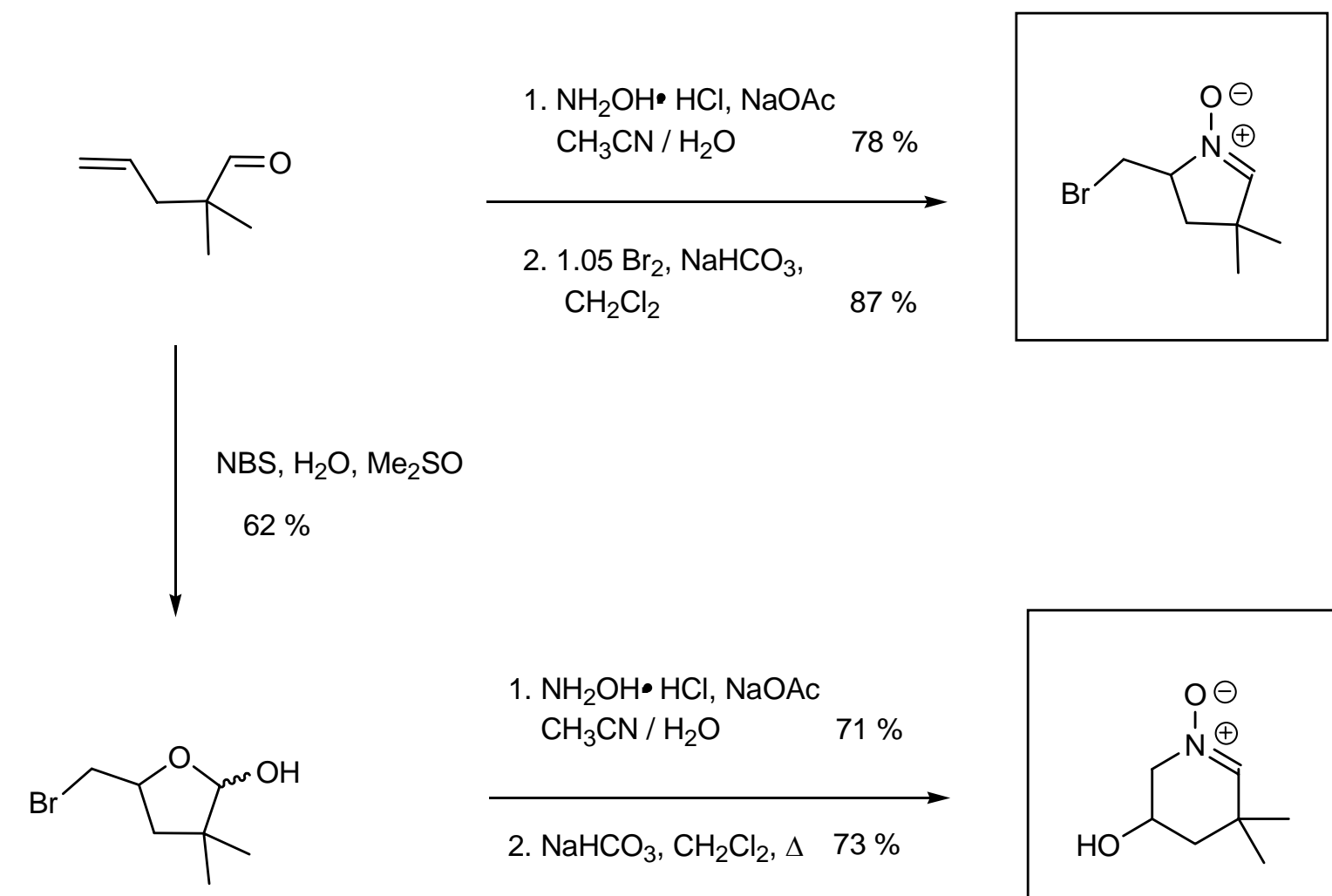

\section{Scheme 9}

\section{Closing remarks}

A number of structurally different $\gamma, \delta$-unsaturated oximes has been shown to undergo bromocyclization to yield bromomethyl-nitrones. Although yields so far are variable and await optimization in some cases, these new pyrroline $\mathrm{N}$-oxides constitute attractive intermediates for applications in synthesis (Scheme 10). With a $\beta, \gamma$-butene aldoxime the $\beta$-bromopyrroline $\mathrm{N}$ oxide was obtained, the formal product of a rare endo-cyclization. Most likely this is due to a change in mechanism that the cyclizing step occurs with the dibromide and not with the bromonium ion intermediate. A directed reversal of the over-all cyclization, to occur at the terminal carbon, has been achieved by switching the reaction sequence: First addition of 
bromine/ $\mathrm{OH}$ to the $\mathrm{C}=\mathrm{C}$ bond of the unsaturated aldehyde, and then oxime formation with subsequent N-cyclization. - Many applications and extensions of this bromocyclization and its regio-reversal are ahead, with the known, rich chemistry of nitrones for stereoselective C-C formation, and also - hopefully - new reactions of nitrones with the bromomethyl group present here and the many other functionalities that are tolerated in these key steps.<smiles>C[C@H]1[C@@H](O)[C@@H](O)CN1O</smiles>

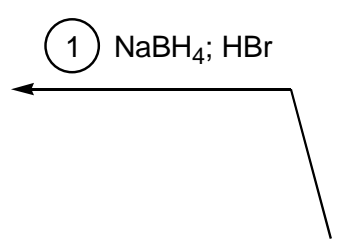<smiles>C[C@H]1[C@H](O)[C@@H](O)CN1O</smiles>

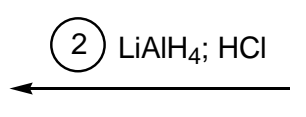<smiles>CI</smiles>

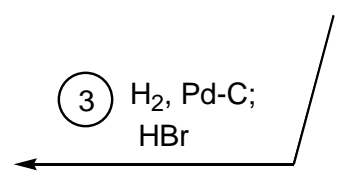

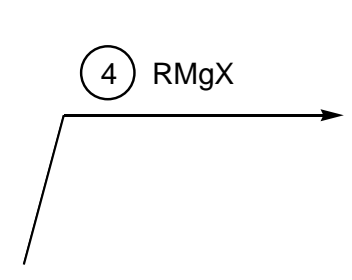<smiles>[R]C1[C@@H](O)[C@@H](O)[C@@H](C)N1O</smiles><smiles>C[C@@H]1NC[C@@H](O)[C@@H]1O</smiles><smiles>CC1(C)O[C@H]2C=[N+]([O-])[C@H](CBr)[C@H]2O1</smiles>

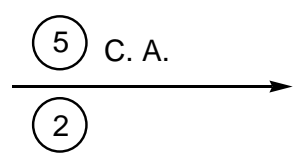<smiles>[R]C1C[C@H]2[C@@H](O)[C@@H](O)[C@@H](C)N2O1</smiles>

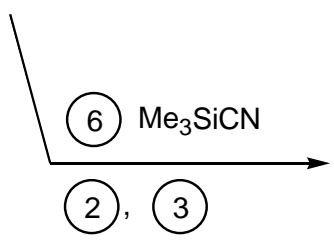

Scheme 10. Uses of bromomethyl-L-lyxo-nitrone, survey.

\section{Acknowledgements}

Initial work on iodocyclization was possible thanks to Alexander von Humboldt Foundation granting a fellowship to Dr. D. Shaw. We also thank Mr. Juan A. Matés Valdivielso, University of Zaragoza, for experimental help (DAAD short-term research fellowship 2002). For financial support of this work we are grateful to Fonds der Chemischen Industrie, Volkswagen-Stiftung (Hannover), to Bayer AG (Wuppertal), and to the EU COST D13 action ("Molecules for Health"). 


\section{References and Notes}

1. (a) Merino, P. In Science of Synthesis; Padwa, A.; Ed., Georg Thieme Verlag: Stuttgart, Germany, 2004; Vol. 27; Chapter 13 (Nitrones and Analogues), pp 511-580. (b) Jones, R. C. F. In Synthetic Applications of 1,3-Dipolar Cycloaddition Chemistry Towards Heterocycles and Natural Products; Padwa, A., Pearson, W. H., Eds., Wiley: New York, USA, 2002, Chapter 1 (Nitrones) pp 1-81. (c) Torssell, K. B. G. Nitrile Oxides, Nitrones, and Nitronates in Organic Synthesis; VCH: Weinheim, Germany, 1988.

2. (a) Carbohydrate Mimics; Chapleur, Y., Ed.; Wiley-VCH: Weinheim, Germany, 1988. (b) Iminosugars as Glycosidase Inhibitors; Stütz, A. E., Ed.; Wiley-VCH: Weinheim, Germany, 1999. (c) Truscheit, E.; Frommer, W.; Junge, B.; Müller, L.; Schmidt, D. D.; Wingender, W. Angew. Chem. 1981, 93, 738; Angew. Chem. Int. Ed. Engl. 1981, 20, 744. (d) Sinnott, M. L. Chem. Rev. 1990, 90, 1171-1202. (e) Legler, G. Adv. Carbohydr. Biochem. 1990, 48, 319384. (f) Fleet, G. W. J. Top. Med. Chem. 1988, 65, 149. (g) Winchester, B.; Fleet, G. W. J. Glycobiology 1992, 2, 199. (h) Heightman, T. D.; Vasella, A. T. Angew. Chem. 1999, 111, 794; Angew. Chem. Int. Ed. Engl. 1999, 38, 750. (i) Jäger, V.; Müller, R.; Leibold, T.; Hein, M.; Schwarz, M.; Fengler, M.; Jaroskova, L.; Pätzel, M.; Le Roy, P.-Y. Bull. Soc. Chim. Belg. 1994, 103, 491. (j) Karanjule, N. S.; Markad, S. D.; Sharma, T.; Sabharwal, S. G.; Puranik, V. G.; Dhavale, D. D. J. Org. Chem.. 2005, 70, 1356, and references given therein.

3. Jäger, V.; Bierer, L.; Dong, H.-Q.; Palmer, A.; Shaw, D.; Frey, W. J. Heterocycl. Chem., 2000, 37, 455.

4. See for example: McCaig, A. E.; Wightman, R. H. Tetrahedron Lett. 1993, 24, 3939.

5. See for example: (a) Peer, A.; Vasella, A. Helv. Chim. Acta 1999, 82, 1044.

6. (a) Armstrong, P.; Grigg, R.; Surendrakumar, S.; Warnock, W. J. J. Chem. Soc., Chem. Commun. 1987, 1327. (b) Hall, A.; Meldrum, K. P.; Therond, P. R.; Wightman, R. H. Synlett 1997, 123. (c) Grigg, R.; Markandu, J.; Perrior, T., Surendrakumar, S.; Warnock, W. J. Tetrahedron 1992, 48, 6929. (d) Ishikawa, T.; Tajima, Y.; Fukui, M.; Saito, S. Angew. Chem. Int. Ed. Engl. 1996, 35, 1863. (e) Herzegh, P.; Korvács, I.; Szilágyi, L.; Varga, T.; Dinya, Z.; Sztaricskai, F. Tetrahedron Lett. 1993, 34, 1211.

7. (a) Markandu, J.; Dondas, H. A.; Frederickson, M.; Grigg, R. Tetrahedron 1997, 38, 13165.

(b) Dondas, H. A.; Frederickson, M.; Grigg, R.; Markandu, J.; Thornton-Pett, M. Tetrahedron 1997, 42, 14339.

8. Holzapfel, C. W.; Crous, R. Heterocycles 1998, 48, 1337.

9. Closa, M.; Wightman, R. H. Synth. Commun. 1998, 28, 3443.

10. Chevrier, C.; LeNouen, D.; Neuburger, M.; Defoin, A.; Tarnus, C. Tetrahedron Lett. 2004, 45, 5363.

11. Grigg, R.; Hadjisoteriou, M.; Kennewell, P.; Markandu, J.; Thornton-Pett, M. J. Chem. Soc., Chem. Commun. 1992, 1388.

12. (a) Grigg, R.; Hadjisoteriou, M.; Kennewell, P.; Markandu, J. J. Chem. Soc., Chem. Commun. 1982, 1537. (b) Dondas, H. A.; Grigg, R.; Hadjisoteriou, M.; Markandu, J.; 
Thomas, W. A.; Kennewell, P. Tetrahedron 2000, 56, 10087. (c) Dondas, H. A.; Grigg, R.; Thibault, S. Tetrahedron 2001, 57, 7035.

13. Frederickson, M.; Grigg, R.; Markandu, J.; Thornton-Pett, M.; Redpath, J. Tetrahedron 1997, 53, 15051.

14. (a) Grigg, R.; Hadjisoteriou, M.; Kennewell, P.; Markandu, J. J. Chem. Soc., Chem. Commun. 1993, 1340. (b) Dondas, H. A.; Grigg, R.; Hadjisoteriou, M.; Markandu, J.; Kennewell, P.; Thornton-Pett, M. Tetrahedron 2001, 57, 1119.

15. (a) Kleban, M.; Hilgers, P.; Greul, J.; Kugler, R.; Li, J.; Picasso, S.; Vogel, P.; Jäger, V. ChemBioChem 2001, 2, 365. (b) Greul, J.; Kleban, M.; Schneider, B.; Picasso, S.; Jäger, V. ChemBioChem 2001, 2, 368.

16. See also: Gartenmann, L.; Leroy, E.; Reymond, J.-L. Org. Biomol. Chem. 2004, 2, 1217 and earlier papers cited.

17. (a) Shaw, D. S.; Jäger, V. Unpublished results; 1994/5. (b) Frey, W.; Bierer, L.; Shaw, D. S.; Jäger, V. Z. Kristallogr. 1998, 213, 577.

18. Bierer, L. Dissertation, Universität Stuttgart/Germany, 1999.

19. (a) Lemieux, R. U.; Morgan, A. R. Can. J. Chem. 1965, 43, 2190. (b) Simonot, B.; Rousseau, G. J. Org. Chem. 1993, 58, 4. (c) Simonot, B.; Rousseau, G. J. Org. Chem. 1994, $59,5912$.

20. Frey, W.; Bierer, L.; Jäger, V. Z. Kristallogr. NCS 2003, 218, 107. (b) Frey, W.; Redcliffe, J. L.; Jäger, V. Z. Kristallogr. NCS 2003, 218, 109.

21. Schmidt, S., Dissertation, Universität Stuttgart/Germany, 2005.

22. (a) Jäger, V.; Schohe, R.; Paulus, E. F. Tetrahedron Lett. 1983, 24, 5501. (b) Houk, K. N.; Moses; S. R., Wu, Y.-D.; Rondan, N. G.; Jäger, V.; Schohe, R.; Fronczek, F. R. J. Am. Chem. Soc. 1984, 106, 3880. (c). Houk, K. N.; Duh, H.-Y.; Wu, Y.-D.; Moses, S. R. J. Am. Chem. Soc. 1986, 108, 2754. (d) Finn, M. G.; Sharpless, K. B., In Asymmetric Synthesis, J. D. Morrison, ed.; Vol. 5, Chapter 8, p 247 ff., in particular p 281, Academic Press: Orlando, USA, 1985. (e) Eyer, M.; Seebach, D. J. Am. Chem. Soc. 1985, 107, 3601. (f) Jäger, V.; Colinas, P. In The Chemistry of Heterocyclic Compounds, Padwa, A., Pearson, W. H., eds.; Vol. 59, Chapter 6, pp 361-472, Wiley: New York, USA, 2002.

23. Jäger, V.; Redcliffe, J. L.; Gulla, M.; Bierer, L. 20 ${ }^{\text {th }}$ ICHC: Palermo, Italy; Book of Abstracts, 4-IL23, p 141.

24. (a) Eliel, E.; Wilen, S. H. Stereochemistry of Organic Compounds; Wiley: New York, USA, 1994, pp 682-684. (b) See also: Günther, H. J.; Jäger, V.; Skell, P. S. Tetrahedron Lett. 1977, 2539. (c) Günther, H. J.; Guntrum, E.; Jäger, V. Liebigs Ann. Chem. 1984, 15.

25. (a) Bartlett, P. A. In Asymmetric Synthesis; Morrison, J. D., Ed.; Chapter 6 (Olefin Cyclization Processes That Form Carbon-Heteroatom Bonds), pp 411-454; Academic Press, Orlando: USA, 1984. (b) Cardillo, G. In Houben-Weyl, Methods of Organic Synthesis; Helmchen, G., Hoffmann, R. W., Mulzer, J., Schaumann, E.; Eds.; Vol. E21e, Chapter 4.6.1 (Lactonization), pp 4704-4759; Thieme: Stuttgart, Germany, 1995. 
26. Dondas, A. H.; Grigg, R.; Markandu, J.; Perrior, T.; Suzuki, T.; Thibault, S.; Thomas, W. A.; Thornton-Pett, M. Tetrahedron 2002, 161.

27. (a) Baldwin, J. E. J. Chem. Soc., Chem. Commun. 1976, 734, 736. (b) Baldwin, J. E. In Further Perspectives in Organic Chemistry; Ciba Foundation Symposium 53; Elsevier: Amsterdam, Netherlands, 1978, pp 85-92. (c) Baldwin, J. E.; Lusch, M. J. Tetrahedron 1982, 38, 2939.

28. (a) Verboom, W.; Reinhoudt, D. N. Bull. Soc. Chim. Fr. 1990, 127, 704. (b) Cf. Goti, A. Tetrahedron 1996, 52, 9187.

29. Greenberg, A.; Liebman, J. F. Strained Organic Molecules; Academic Press: New York, USA, 1978; p 94.

30. Encyclopedia of Reagents for Organic Synthesis; Paquette, L. A., Ed.; Wiley: Chichester, UK, 1995; Vol. 1, pp 768-736. 